\section{The Members have spoken...}

Peter Ward

BDA Chief Executive
Send your comments to the

Editor-in-chief,

British Dental Journal

64 Wimpole Street,

London,

W1G 8YS

Email bdj@bda.org
It seems like a long time ago when we started talking about the differentiating needs of the UK dental profession and what their expectations are. In fact, we can look back four years when we began a deep and thorough examination of the current dental landscape and how the BDA needed to change to meet the demands of the modern profession. It was plain to see that the profile of the profession was changing and that attitudes to work and careers were beginning to look very different to previous generations. Add to that greater differentiation of the four countries of the United Kingdom, and how they do business and govern themselves, and it became clear that a 'one size fits all' type membership was not sustainable or appropriate for a modern BDA. Instead we needed to get under the skin of the different cohorts of the profession and find out what was important to them. For some the predominant feature was price, for others it was service. And when it came to service, it was apparent that different dentists required different types and levels of service. So we concluded that we needed to produce differentiated offerings that matched the demands of those groups - with different content and different price points.

That exercise was hugely complex and took some considerable time. What it resulted in was a three-tiered system of membership that provides an entry level offering, one that adds personal bespoke advice, and one that offers a complete solution in terms of managing the compliance and operational demands of running a practice. All packages were differentially priced and members were offered the freedom to select which ever package best matched their needs. They were also offered the opportunity to 'upgrade' their membership package at any time without penalty should the need arise. We felt that this latter condition was an important one for a membership organisation that needs to be there for its members when they need it. We gave the launch major publicity and provided our members with as much information as we could so that they could make an informed choice about which package to choose to suit them. If you think about it, what this represented was the ultimate in the context of a customer survey. We were saying; here is the range of options, here are the contents and here are the prices - now you choose what you want, for now. And the 'for now' is important because we were also saying, should the need arise or your preferences change you can change your mind and get the extra services that you need.

\section{HIGHLY RESPECTED EXPERTISE}

As a result of all this analysis and effort our members did indeed exercise their choices. Our background research which had demonstrated that a number of our members and prospective members were being put off by price was proved right as many members expressed a preference for a lower cost, reduced service (but still high content) package. But many others elected immediately to avail themselves of our very highly respected expertise advice and bespoke services. of course these are early days and this description is just a snapshot of where we have begun. We are already conscious of a return to membership by people who have lapsed and new recruits who have been attracted by the new arrangements. As the message spreads and needs change, we are also observing members upgrade their memberships to avail themselves of the more bespoke aspects of our offerings.

Specifically one of the areas we turned our attention to was our student membership and what we could offer to the up and coming generation of dentists at a time when they are entering the profession, and when the world around them is full of change and challenges. We radically redesigned student membership and whilst this was launched at the same time as full launch we will be proudly presenting the new offer to the student caucus when term starts in the autumn.

So, the dust has not completely settled yet, but what we are now beginning to work on is the shape of BDA that our members have told us that they really want at the outset. By their choices they have told us how many want generic services and how many want tailored bespoke offerings. Armed with that information we will now re-design the BDA to match those expectations. We will re-organise ourselves so that we can deliver to those expectations effectively and sustainably making sure that what we offer is affordable to members and of high quality. The new shape will provide us with the flexibility to scale up or down our offerings directly in the light of member need and demand and will make sure that the BDA retains its relevance to all dentists working in the UK.

Dentistry, alongside other areas of the UK landscape has become a challenging place in which to work. Dentists need a strong collective voice. They also need services and offerings that are tailored to their needs. Owned by its members, with their support as its only mission, the BDA is now geared to provide them with the services that they have demanded and selected. Together we are stronger.

DOI: 10.1038/sj.bdj.2013.743 